\title{
A public health frame arouses hopeful emotions about climate change
}

\section{A Letter}

\author{
Teresa A. Myers - Matthew C. Nisbet • Edward W. Maibach • Anthony A. Leiserowitz
}

Received: 18 January 2012 / Accepted: 22 May 2012 /Published online: 28 June 2012

C The Author(s) 2012. This article is published with open access at Springerlink.com

\begin{abstract}
Communication researchers and practitioners have suggested that framing climate change in terms of public health and/or national security may make climate change more personally relevant and emotionally engaging to segments of the public who are currently disengaged or even dismissive of the issue. To evaluate these assumptions, using a nationally representative online survey of U.S. residents $(N=1,127)$ conducted in December, 2010, we randomly assigned six previously identified audience segments on climate change to one of three experimental conditions. Subjects were asked to read uniquely framed news articles about climate change emphasizing either the risks to the environment, public health, or national security and the benefits of mitigation and adaptation-related actions. Results show that across audience segments, the public health focus was the most likely to elicit emotional reactions consistent with support for climate change mitigation and adaptation. Findings also indicated that the national security frame may possibly boomerang among audience segments already doubtful or dismissive of the issue, eliciting unintended feelings of anger.
\end{abstract}

\section{Introduction}

Effectively engaging the American public on climate change-including its causes, impacts, and solutions - remains both a major research question and a communication challenge.

Electronic supplementary material The online version of this article (doi:10.1007/s10584-012-0513-6) contains supplementary material, which is available to authorized users.

T. A. Myers • E. W. Maibach

Center for Climate Change Communication, George Mason University, Fairfax, VA 22030, USA

T. A. Myers

e-mail: tmyers6@gmu.edu

M. C. Nisbet $(\bowtie)$

School of Communication, American University, Washington, DC 20016, USA

e-mail: nisbet@american.edu

A. A. Leiserowitz

School of Forestry, Yale University, New Haven, CT 06511, USA 
Effective public engagement requires understanding the cognitive, affective, and behavioral nature of audiences (Lorenzoni et al. 2007). In this paper we focus on the affective dimension of climate change engagement - a dimension that has received little research attentionexamining the potential for various frames to elicit emotional reactions consistent with climate change mitigation and adaptation goals.

Social scientists have long understood that the way an issue is framed has important consequences (Goffman 1974; Gamson and Modigliani 1989). Framing-whether intentional or not - involves selectively emphasizing certain dimensions of an issue over others, setting the context for perception and discussion around specific causes, risks, policy actions, and costs/benefits that might result from these actions. The frame used suggests both the diagnosis of the problem as well as prescriptions for what should be done about it (Nisbet 2009; Scheufele 1999). Moreover, the way an issue is framed-in the media or in other communications - interacts with audience members' pre-existing schema, mental models and values. As a consequence, a specific message frame is particularly influential to the extent that it is relevant — or applicable — to the audience's preexisting predispositions and perceptions (Nisbet and Scheufele 2009; Scheufele 1999).

Recent analyses of the U.S. public have mapped how climate change-related predispositions and perceptions vary across six distinct 'interpretive communities' of individuals called "Global Warming's Six Americas" (Maibach et al. 2010). These audience segments range along a continuum of knowledge, attitudes, and behavior, from the Alarmed (who accept climate change as a problem, are concerned, and who are looking for opportunities to take personal and political action) to the Dismissive (who reject the reality of climate change and strongly oppose action). Individuals in the four interpretive communities in the middle of the continuum are less certain in their views on climate change, more ambivalent about the risks and relative importance of the issue, and more likely to be disengaged personally and politically. (See Fig. 1 for the most recent distribution of the American public across these six segments; Leiserowitz et al. 2011).

Climate change has historically been framed as an environmental problem. More recently, it is increasingly being framed as a political problem. Social scientists, however, have suggested a variety of potential alternative frames, each of which can validly and accurately emphasize other relevant dimensions of the issue - such as public health, national security, extreme weather events, and/or the economy (Nisbet 2009; Nisbet and Scheufele 2009; Maibach et al. 2010). Such alternative frames may be more effective at engaging audiences than the environmental or political frames that currently dominate public discourse.

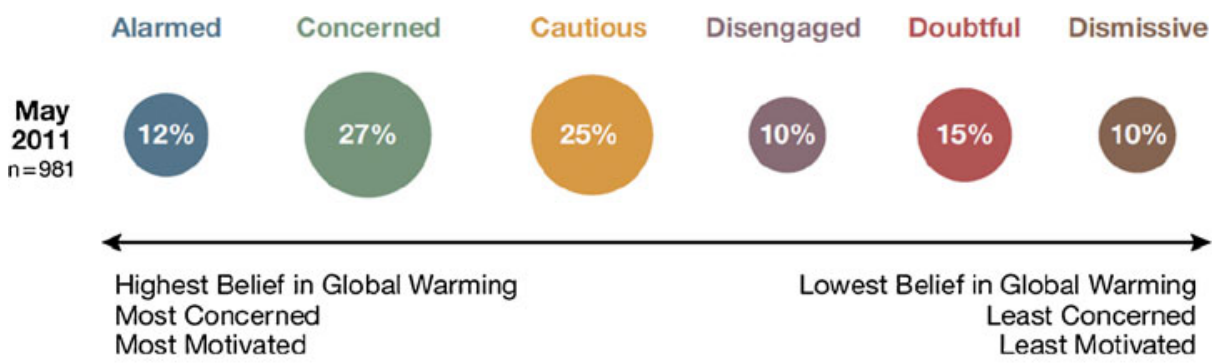

Proportion represented by area

Source: Yale/George Mason University

Fig. 1 Global warming's six Americas. Source: Yale/George Mason University 
Research on a public health frame, for example, suggests that when climate change is introduced as a human health issue, a broad cross-section of audiences-even segments otherwise skeptical of climate science-find the information to be compelling and useful (Maibach et al. 2010). Framing research can identify not only which frames are likely to be effective, and with whom, but also which are likely to "boomerang." For example, several studies find that messages emphasizing catastrophic, dire consequences or threats that are geographically remote can result in less concern and more hopelessness among audiences (Hart and Nisbet 2011; O’Neill and Nicholson-Cole 2009).

People's emotional reactions to messages about climate change are an important consideration, yet to date they have often been overlooked both in research and in communication efforts. Thagard and Findlay (2011) argue that "encouraging belief change....about climate change requires dealing with emotional constraints as well as cognitive ones" (p. 342) and Markowitz and Shariff (2012) identify positive emotional appeals as one of the most promising strategies for climate change communication. Indeed, emotional responses to novel information occur effortlessly and almost instantaneously, influencing subsequent cognitive processing of information (Kahneman 2011).

Emotions serve as affective prompts for engagement with an issue and lead to forming predispositions for action when a relevant situation arises (Baumeister et al. 2007). Furthermore, emotions themselves can serve as frames by which future information is interpreted (Nabi 2003). Negative emotions, such as anger or fear, motivate us to the need to be on "high-alert" and to seek more information about an issue (Baron et al. 1994), can lead to greater risk perceptions and greater policy support (Leiserowitz 2006), and have the potential to transform apathy or indifference into perceived importance and behavioral action (Thomas et al. 2009).

However, eliciting anger against the claims or proposed recommendations emphasized in a communication strategy also has the danger of inciting action counter to the communicator's intent. Moreover, the effect of arousing anger is likely not uniform across audience segments, as the target and content of an individual's anger may vary. For instance, topics that elicit anger among people alarmed about climate change might include how ecosystems, disadvantaged people, and specific social groups are being harmed. By contrast, the very claim of climate change's reality might elicit anger among people dismissive of the issue. Thus, a given message could generate an angry backlash by some recipients, leading to an unintended social response, while provoking an equally angry-yet intended-social response by other recipients.

Positive emotions can also play an important role in message response (Monahan 1995). Feelings of hope related to climate change, for example, likely increase the probability that individuals will choose to engage with the issue and adopt beliefs and behaviors consistent with efforts to stem the problem (Markowitz and Shariff 2012; Snyder 2002; Swim et al. 2010). Hope is often aroused as perceptions of efficacy, the belief that an individual has the capacity to implement a proposed response to a threat and that the recommended action can effectively mitigate the threat, increase (Bandura 1977). Feelings of hope and efficacy are strongly correlated with a willingness to engage in pro-environmental behaviors and to support climate change policies (Lorenzoni et al. 2007). Conversely, feelings of hopelessness and inefficacy related to climate change are linked with a tendency to ignore the problem or to rationalize inaction (Norgaard 2011).

With these considerations in mind, in this study we investigate how unique audience segments - Global Warming's Six Americas - emotionally react to news articles crafted to reflect three distinct climate change message frames: (1) a traditional environmental frame, which emphasizes the consequences of climate change to ecosystems - and the benefits to ecosystems of adaptation and mitigation-related actions, (2) a national security frame, which highlights the risks to U.S. national security and the benefits to national security of 
adaptation and mitigation-related actions and (3) a health frame, which stresses the health risks associated with climate change and the potential benefits to health of adaptation and mitigation-related actions.

\section{Method}

In order to assess how members of different audience segments responded to three distinct message frames, we conducted a randomized, controlled message experiment using a nationally representative online sample of 1,127 individuals. Participants were randomly assigned to read one of three specifically framed articles each of approximately 610 words, structured identically, but emphasizing different dimensions of the climate change problem. Among subjects, 376 participants (33\%) were asked to read an article emphasizing the environmental dimension, 351 participants $(31 \%)$ were asked to read an article emphasizing national security, and 400 participants $(36 \%)$ were shown a message emphasizing the health dimension [See Supplementary Materials for more detail about the sample and the text of the articles].

\subsection{Six Americas audience segmentation}

Following the methodology presented in Maibach et al. (2011), participants were categorized into one of six audience segments based on their existing climate change-related attitudes, beliefs, knowledge, preferences, and behaviors. These segments included the Alarmed (180 participants, $16 \%)$, Concerned (235, $21 \%)$, Cautious (245, $22 \%)$, Disengaged $(115,10 \%)$, Doubtful $(191,17 \%)$, or Dismissive $(161,14 \%)$.

\subsection{Emotional reaction}

In each condition, respondents were asked to indicate which parts of the framed message made them feel hopeful and which parts of the message made them feel angry by clicking on those sentences. The number of sentences that respondents clicked for each emotion was summed to create a separate Hopeful and Angry measures.

\subsection{Analysis}

To test respondents' emotional reactions to the environment, public health, and national securityframed messages, interaction terms were created (using dummy codes), multiplying segment by frame. (The reference category was rotated across each analysis to allow for comparison of all groups.) Models predicting the emotional responses of hope and anger were fit using Poisson regression (as is appropriate for count data). All models were weighted with a post-stratification weight to match national demographic and audience segmentation characteristics.

\section{Results}

\subsection{Predicting hope}

First, using audience segment and message frame as predictors, a model was fit to predict the number of hope-inducing sentences (complete model results shown in online supplemental 
material, Table 1). Both were significant predictors, although message frame was only marginally significant.

Controlling for audience segment, the health frame was the most likely to generate feelings of hope, followed by the environment frame, and then the national security frame. However, the frame that gave respondents the most hope differed by audience segment (see Fig. 2). Of particular note, the health frame generated more hope than either the environment or national security frames among the Cautious, Disengaged, and Dismissive segments (see online supplemental material, Table 2). The Alarmed found high levels of hope in all the messages with slightly more hope in the national security frame, while the Concerned found the most hope in the environment message. Overall, consistent with their pre-existing orientations, the audience segments on the left end of the spectrum responded more hopefully than those on the right.

\subsection{Predicting anger}

Next, again using audience segment and message frame as predictors, a model was fit to predict the number of anger-inducing sentences (complete model results shown in online supplemental material, Table 1). Both audience segment and message frame were significant predictors.

Controlling for audience segment, the national security message was the most likely to generate anger, followed by the environment message, while the health message generated the least amount of anger. The frame that caused respondents to feel the most anger differed by audience segment (see Fig. 3 and online supplementary materials, Table 3).] Overall, the Dismissive experienced the most anger. However, they also had the most between-frame variation in their anger responses: the national security frame elicited the most anger, and the public health frame the least. The Doubtful also reacted most angrily to the national security frame, and least angrily to the health frame. The Disengaged and the Cautious indicated relatively limited amounts of anger, regardless of the message frame. ${ }^{1}$ Among the Concerned, the environment frame generated more anger than the national security frame, and the health frame generated the least anger. The Alarmed were most likely to experience anger in response to the national security frame.

\section{Discussion}

Our findings are consistent with past scholarship describing the influence of different message frames in public responses to climate change (Nisbet 2009). Our results are also consistent with past research that has found that a diversity of audience segments respond positively to an emphasis on the public health consequences of climate change and the health benefits of action (Maibach et al. 2010). Furthermore, although emphasizing the national security implications of climate change has been assumed to be an effective strategy for engaging conservatives and other groups (Boykoff 2011), our findings show that in this

\footnotetext{
${ }^{1}$ The emotion of anger may lead to quite different actions, depending on the target and content of the anger. It is likely that the anger experienced by audience segments convinced that climate change is occurring will lead to action consistent with adaptation and mitigation goals. However, anger experienced by audience segments unconvinced that climate change is occurring will likely lead to action counter to adaptation and mitigation goals. (Analysis of the anger-producing sentences chosen by each segment supports this perspective. See the sentence analysis in the online supplemental materials. Furthermore, analysis of the influence of anger on support for reducing US emissions shows that the effects differed by segment-see Fig. 2 in the online supplemental materials).
} 


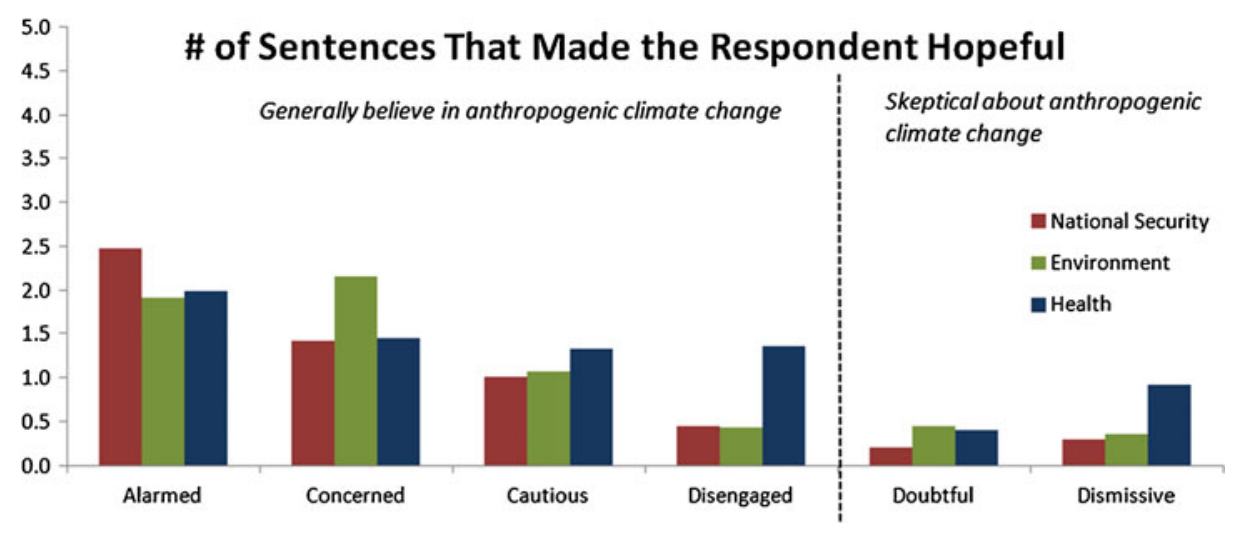

Fig. 2 Feelings of hope by frame condition across audience segment. Note: This figure depicts the estimated marginal means of the sement by frame interaction as generated by the model

instance (for reasons we speculate below) the national security frame actually generated substantial anger among the Doubtful and Dismissive segments of the public, both of whom lean conservative in their political outlook. Importantly, an emphasis on the environmental risks of climate change-historically the dominant frame in climate change communication efforts - neither inspired hope nor balanced out feelings of anger among the Disengaged, Doubtful, and Dismissive segments of the public.

Across all audience segments, participants who read the public health message reacted with at least some feelings of hope. Overall, $57 \%$ of all subjects assigned to the health frame responded hopefully to the following proposed action, suggesting that a localization of the issue may also be an important element of effective communication (see supplemental materials Table 4 "Top Hopeful Statements by Frame and Across Audience Segment” for details):

Redesigning our cities and towns to make it easier and safer to travel by foot, bicycle and public transportation will reduce the number of cars on the road, reduce carbon dioxide emissions, reduce traffic injuries and fatalities, and help people become more physically active, lose weight, strengthen their bones, and possibly even to remain mentally sharp as they age.

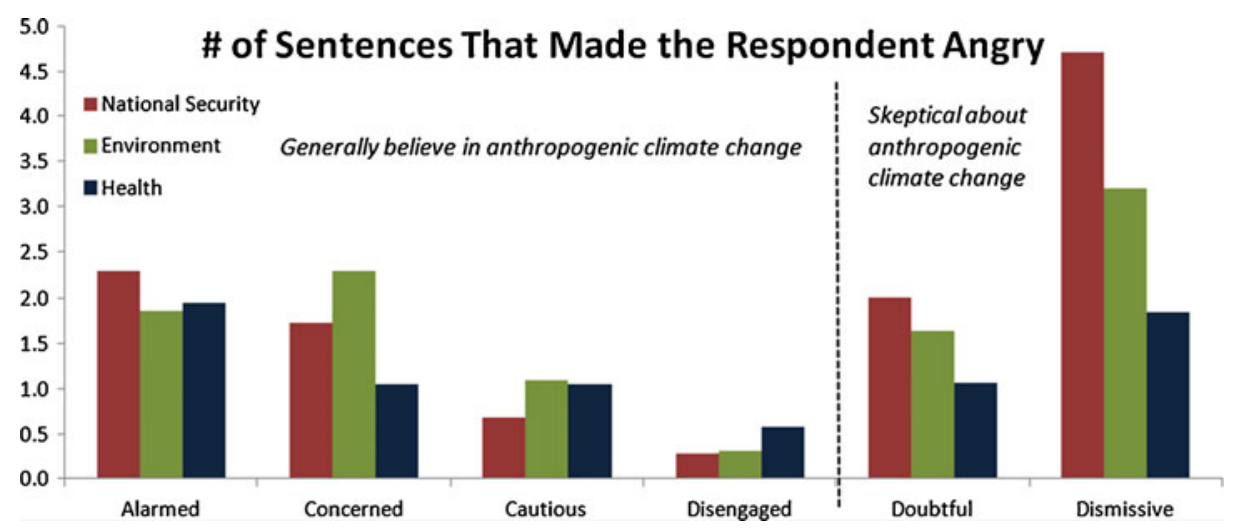

Fig. 3 Feelings of anger by frame condition across audience segment. Note: This figure depicts the estimated marginal means of the sement by frame interaction as generated by the model 
The results also suggest that the national security frame may generate an angry backlash, especially among segments already Doubtful or Dismissive of climate change. Across the three different frame conditions, the top two anger-producing sentences among the Doubtful and Dismissive were both about national security (see supplemental materials Table 5 "Top Angry Statements by Frame and Across Audience Segment" for details):

The most recent Quadrennial Defense Review - a national security report prepared every four years by the Pentagon for the U.S. Congress - concludes that global warming is a 'key issue' likely to harm U.S. national security in many ways.

They also argue that efforts to limit global warming are a 'win-win' because they will reduce the risks of global warming and improve America's national security.

Very few members of the other segments reacted angrily to these two statements. It is possible that members of the Doubtful and Dismissive segments perceived the article to be an attempt to make a link between an issue they may care deeply about (national security) and an issue that they tend to dismiss (climate change), or they felt the article was attempting to co-opt values they care strongly about, thereby producing a negative reaction. Alternatively, it may be that participants were experiencing anger toward the experimenters for having presented claims about global warming and national security that they as respondents did not perceive as authentic or credible. Further research needs to be conducted to understand the nature and extent of this potential boomerang effect.

Finally, outside of this experimental condition, in the context of real world communication efforts, these effects may differ due to a variety of factors. One particularly important factor is the messenger, specifically the congruence between the messenger and the frame. Other potentially important factors include whether the message is delivered by the media or face-to-face, the availability of competing frames or arguments, the nature of any policy actions proposed to address the problem, and the salience of other linked trends-particularly those involving the economy and/or political polarization more generally.

Our study, overall, underscores the importance of careful theoretical and empirical investigation of how climate change communication efforts differentially shape Americans' views, understanding, and preferences on climate change. This research demonstrates the potential of the public health frame to inspire hope in the context of the climate change discussion, while simultaneously demonstrating the possibility that certain frames may be poorly received within some interpretive communities. More research is needed to understand how frames both set the context for perception on the issue and interact with emotions in guiding public decisions and behavior

Acknowledgments This study was supported by a Robert Wood Johnson Foundation Health Policy Investigator Award and by the Grantham Foundation for the Protection of the Environment.

Open Access This article is distributed under the terms of the Creative Commons Attribution License which permits any use, distribution, and reproduction in any medium, provided the original author(s) and the source are credited.

\section{References}

Bandura A (1977) Self-efficacy: toward a unifying theory of behavioral change. Psych Rev 34(2):191-215

Baron RS, Logan H, Lilly J, Inman ML, Brennan M (1994) Negative emotion and message processing. J Exp Soc Psych 30:181-201. doi:10.1006/jesp.1994.1009

Baumeister RF, Vohs KD, DeWall CN, Zhang L (2007) How emotion shapes behavior: feedback, anticipation, and reflection, rather than direct causation. PSPR 11:167-203. doi:10.1177/1088868307301033 
Boykoff J (2011 May 20) US military goes to war with climate skeptics. Guardian. http://www.guardian. co.uk/commentisfree/cifamerica/2011/may/20/climate-change-climate-change-scepticism. Accessed 29 August 2011

Gamson WA, Modigliani A (1989) Media discourse and public opinion on nuclear power: a constructionist approach. Am J Soc 95:1-37

Goffman E (1974) Frame analysis: an essay on the organization of experience. Harper \& Row, New York

Hart PS, Nisbet EC (2011) Boomerang effects in science communication: How motivated reasoning and identity cues amplify opinion polarization about climate mitigation policies. Commun Res doi:10.1177/ 0093650211416646

Kahneman D (2011) Thinking fast and slow. Farrar, Straus, and Giroux, New York

Leiserowitz A (2006) Climate change risk perception and policy preferences: the role of affect, imagery, and values. Clim Chang 77:45-72. doi:10.1007/s10584-006-9059-9

Leiserowitz A, Maibach E, Roser-Renouf C, Smith N (2011) Global Warming's Six Americas, May 2011. Yale University and George Mason University. New Haven, CT: Yale Project on Climate Change Communication. http://environment.yale.edu/climate/files/SixAmericasMay2011.pdf Accessed 25 October 2011

Lorenzoni I, Nicholson-Cole S, Whitmarsh L (2007) Barriers perceived to engaging with climate change among the UK public and their policy implications. Glob Environ Chang 17:445-459. doi:10.1016/ j.gloenvcha.2007.01.004

Maibach EW, Nisbet M, Baldwin P, Akerlof K, Diao G (2010) Reframing climate change as a public health issue: an exploratory study of public reactions. BMC Pub Health 10:299. doi:10.1186/1471-2458-10-299

Maibach E, Leiserowitz A, Roser-Renouf C, Mertz CK (2011) Identifying like-minded audiences for climate change public engagement campaigns: An audience segmentation analysis and tool development. PLoS ONE 6(3):e17571. doi:10.1371/journal.pone.0017571

Markowitz EM, Shariff AF (2012) Climate change and moral judgement. Nat Clim Chang. doi:10.1038/ NCLIMATE1378

Monahan JL (1995) Thinking positively: using positive affect when designing health messages. In: Maibach E, Parrott RL (eds) Designing health messages: approaches from communication theory and public health practice. Sage, London, pp 81-98

Nabi RL (2003) Exploring the framing effects of emotion: do discrete emotions differentially influence information accessibility, information seeking, and policy preference? Commun Res 30:224-247. doi:10.1177/0093650202250881

Nisbet MC (2009) Communicating climate change: why frames matter for public engagement. Environ 51:12-23. doi:10.3200/ENVT.51.2.12-23

Nisbet MC, Scheufele DA (2009) What's next for science communication? Promising directions and lingering distractions. Am J Bot 96:1767-1778. doi:10.3732/ajb.0900041

Norgaard KM (2011) Living in denial: Climate change, emotions, and everyday life. The MIT Press, Cambridge

O’Neill S, Nicholson-Cole S (2009) "Fear won't do it": promoting positive engagement with climate change through visual and iconic representations. Sc Comm 30:355-279. doi:10.1177/1075547008329201

Scheufele DA (1999) Framing as a theory of media effects. J Comm 49(1):103-122. doi:10.1111/ j.1460-2466.1999.tb02784.x

Snyder CR (2002) Hope theory: rainbows in the mind. Psych Inq 13:249-275

Swim J, Clayton S, Doherty T, Gifford R, Howard G, Reser J, Stern P, Weber E (2010) Psychology and global climate change: Addressing a multi-faceted phenomenon and set of challenges. A report by the American Psychological Association's Task Force on the Interface between Psychology and Global Climate Change. http://www.apa.org/science/about/publications/climate-change.aspx Accessed 25 August 2011

Thagard P, Findlay S (2011) Changing minds about climate change: Belief revision, coherence, and emotion. In Olsson EJ, Enqvist S (eds.), Belief revision meets philosophy of science. doi:10.1007/ 978-90-481-9609-8

Thomas EF, McGarty C, Mavor KI (2009) Transforming "apathy into movement": the role of prosocial emotions in motivating change. Pers Soc Psychol Rev 13:31-333. doi:10.1177/1088868309343290 